Letter

\title{
WITHDRAWN: Blood Donors in Disasters; the 2017 Kermanshah Earthquake
}

\author{
Ali Sahebi (iD) ${ }^{1, *}$ and Kosar Yousefi ${ }^{2}$ \\ ${ }^{1}$ Department of Health in Disasters and Emergencies, School of Public Health and Safety, Shahid Beheshti University of Medical Sciences, Tehran, Iran \\ ${ }^{2}$ Student Research Committee, Department of Nursing, Ilam University of Medical Sciences, Ilam, Iran \\ "Corresponding author: Department of Health in Disasters and Emergencies, School of Public Health and Safety, Shahid Beheshti University of Medical Sciences, Tehran, Iran. \\ Email: nurse.sahebi@yahoo.com
}

Received 2019 April 15; Accepted 2019 April 20.

Keywords: Blood Transfusion, Disasters, Donors, Earthquakes, Health Care Facilities, Management, Organization, Planning

This article is withdrawn by authors request. 